\title{
THE INFLUENCE OF TEACHER SKILLS ON 16-YEAR-OLDS
}

\author{
Eyvind Elstad, Knut-Andreas Christophersen, Are Turmo \\ University of Oslo, Oslo, Norway \\ E-mail: eyvind.elstad@ils.uio.no, k.a.christophersen@stv.uio.no, \\ are.turmo@gmail.com
}

\begin{abstract}
In a school system in which young people receive an ever greater degree of self-determination, it is important to study how the teacher can influence young people's motivation to work towards long-term goals in schoolwork. The purpose of this study is to investigate which teaching skills influence the volition of 16-year-olds. Structural equation modelling of cross-sectional surveys from one survey was used to estimate the path coefficients. The influence of teachers'skills on 16-year-olds'volition was estimated. The analysis indicates that the teacher's perceived ability to influence pupil volition is present, but modest. Classroom management has a moderately-high effect on pupil volition, whilst the teacher's press has only a moderate effect on pupil motivation. The teacher's relationship-building efforts have little effect on either pupil motivation or volition. The indirect effect from pupil motivation to pupil volition is of moderately-high strength. However, a cross-sectional study does not allow us to test causal relationships amongst personal antecedents of pupil volition. Teachers may exercise some influence over 16-year-olds' volition primarily by means of classroom management, but also in terms of pupil motivation via teacher press. Teachers may exploit this capacity to influence in order to improve pupil performance at school. For pupils lacking academic motivation, the teacher's efforts to motivate and to strengthen pupil volition are important, including in terms of social levelling. The study provides new knowledge about teacher influence on the volition of Norwegian 16-year-olds.
\end{abstract}

Key words: adolescence, classroom management, motivation, Norway, teacher press, teacher's relational building, volition, youth.

\section{Introduction}

At present the social-cognitive theory perspective has a strong position in the field of educational psychology, and the concept of self-regulated learning (SRL) is in vogue (Boekaerts, 1999). There is extensive literature on SRL. SRL theories are often viewed as a function of learning strategies, motivation, volition, and metacognition, bridging several strands of psychological research (Boekaerts \& Corno, 2005; Wolters, 2003; Pintrich, 2000). "All theorists assume that students who self-regulate their learning are engaged actively and constructively in a process of meaning generation and that they adapt their thoughts, feelings, and actions as needed to affect their learning and motivation" (Boekaerts \& Corno, 2005, p. 201). The basis of SRL theories is that it is valuable for the development of agency and ability that the student accomplishes setting personal goals for learning (hereafter termed goal-driven motivation) and pursues strategies in order to achieve these goals (hereafter termed volition). 
PROBLEMS

OF EDUCATION

IN THE $21^{\text {st }}$ CENTURY

Volume 39,2012

Some researchers can understand the latter as implicit and almost a natural consequence of goal-driven motivation (Zimmerman, 2000). Other researchers isolate this as an independent factor which is referred to by several different labels: regulation of motivation (Wolters, 2003), self-discipline (Duckworth \& Seligman, 2005) and volition (Corno, 2000).

Different kinds of psychological theories constitute their own niches. Each model emphasises slightly different aspects of motivation, volition, cognitive processing, et cetera. One of the niche-mileus distinguishes motivational processes from volitional processes (for instance Heckhausen, 1977; Corno, 2000; Kuhl, 1985), and volition is understood as beneficial constraints that pupils impose on themselves. This distinction is supported by experiments (Gollwitzer, 1999) and surveys (McCann \& Turner, 2004, p. 1710). These and other researchers (e.g., Winne, 2004; Corno, 2004; Wolters, 2003) also address volition using a broad view of SRL theory. Research on volitional processes, however, is not tied to any one theoretical perspective, but can be viewed as consistent with several theoretical frameworks. In this article, volition is the endogenous variable of a theoretical approach which emphasises teacher skills as influencing factors. Discounting theory was used as a theoretical framework (Ainslie, 2001).

Traditionally, studies of volition have been closely connected to studies of motivation. Distinctions are often made between motivation and volition (Wolters, 2003). Motivation sometimes refers to an end state, but sometimes also to the means through which that state is determined, and more generally to management of the cognitive processes that govern learners' choice, effort, and persistence. Volition has been partly viewed as an aspect of motivation, whilst partly regarded as a distinct factor in the question of how pupil attitudes lead to action. Here, volition is the actual driving power for translating goal-directed motivation into action by taking self-discipline strategies into action. In this article, the focus is on the school context and in the school it is the teacher who is in the front line and who has the job of influencing pupil motivation and volition in a positive direction.

The Norwegian teacher is to use their personal skills to engage the pupils in the academic work and to produce the motivation to keep working at their learning (White paper, 2008). Therefore, it is interesting to study not only the connection between motivation and volition, but also different aspects of the teacher's performance of their role. This performance can be demonstrated in different tasks typically carried out by the teacher as part of their classroom work. On the one hand, the teacher is to be seen as a leader of the learning processes in the classroom. This has been held up as an important skill in Norwegian policy documents in recent years (White paper, 2008). This skill is referred to as classroom management.

The Norwegian authorities have placed an emphasis on exerting more "pressure to learn" as an important task for the teacher (White paper, 2003). Teacher press is thereby seen as an important skill in the execution of the teacher's role. Furthermore, the teacher's relational skills are of great significance in a Norwegian school context. In Norwegian schools, pupil satisfaction has been valued to a significant degree and pupils have been given some influence in respect to taking care of pupil satisfaction and well-being in the school (White paper, 2008). This skill is referred to as relational building. Relational building is an aspect of the teacher's role which presumably is not emphasised in the school culture of some other countries. One example is Japan, where the teacher generally has greater authority in the eyes of the pupils than is the case in a Norwegian school. In Japanese school culture it is not as important that the teacher creates a good relationship with the pupils. It is the Japanese teacher's authority conferred by their role that provides the teacher with a degree of influence over Japanese pupils' motivation, volition and thus actions (Stigler \& Hiebert, 1999). As such, a distinct cultural feature of the Norwegian school system is highlighted: the ability to build good relationships with the pupils (known as relationship building) is an important skill for the teacher. These three distinct skills within the teacher's role are understood in this study as antecedents for pupil motivation and volition. The purpose of this study is to estimate the strength of these factors in relation to pupil motivation and volition for learning. 
Eyvind ELSTAD, Knut-Andreas CHRISTOPHERSEN, Are TURMO. The Influence of Teacher Skills on Pupil Volition in Science Learning: a Norwegian Investigation of the Studying Behaviours of 16-Year-Olds

Given that Norwegian pupils in upper-secondary school have been given a significant degree of self-determination in respect to managing their own efforts in schoolwork, it is of even greater importance that they are able to take responsibility for their own studies. The theoretical perspective on which this is based is that the various options that the pupil has will be valued differently over the course of time. Pupils at upper-secondary school often set themselves longterm goals, for instance, in regards to choice of higher education. Other goals can apply to the medium and short term; in other words there is a continuum of goals and period perspectives. This is simplified by differentiating between long-term and short-term goals. Humans attribute values to these goals.

Discounting is a way of directly comparing present and future rewards (or punishments). Our decisions require us to weigh consequences that are distributed over time (Kirby \& Herrnstein, 1995). Practically all human beings face 'choice-situations' in which they must choose between immediate and delayed rewards. When humans have choices, they can achieve at different points in time, the relative valuation of the choices is discounted according to expected delays until realisation. Learners who value schoolwork rather than non-academic activity in a lenient regime display consistent behaviour at any point in time. The school-oriented work is valued in a consistent manner over time, and it is valued more highly than non-academic activity. Such learners discount the option of a delayed reward according to an exponential curve, which implies stability of goals over time. Stability in preference structure over time presupposes exponential time discounting which is dynamically consistent: the relative motivational force of the two possible alternatives remains constant as one moves closer to them in time. These learners are self-regulated in their learning efforts.

Wolters (2003) considers self-regulated learners as having a large arsenal of cognitive strategies that they can readily and skilfully deploy to accomplish different academic tasks. These learners have a store of knowledge about cognitive learning strategies specifically, and they have the ability to select, monitor, and regulate their use of those strategies when engaged in academic tasks (Zimmerman, 1998). Learners may develop a range of volitional learning strategies to strengthen their resolve to stifle impulses and bolster good intentions related to their academic work. However, learners may have an acknowledged long-term objective for their education where constant hard work at school is necessary for them to achieve their goal, but they may lack volition for learning. They may deceive themselves in ways that support immediate gratification (high rates of discounting, Ainslie, 2001). Their behaviour is characterised by dynamic inconsistency. This is the modus operandi of weakness of will, and a model of hyperbolic discounting explains the qualitative properties of the classical weakness of will dilemma (Elster, 1979). The subjective value of a delayed reward is inversely related to the length of the postponement (Ainslie, 2001), a hyperbolic pattern that has been observed in extensive research on human decisions (Green \& Myerson, 2004) since individuals have a tendency to attach more importance to rewards in the near future (myopia) than to rewards in the distant future. The preferences and beliefs learners have that are linked to goals may therefore be unstable in the sense that volitional processes influence the motivational impact of learners' goals.

There may be several models that explain dynamic inconsistency. One of the explanatory models is the model of hyperbolic discounting where the preference reversal is induced by the sheer passage of time. For disaffected learners there is often a motivational conflict between an immediate option that seems to loom too large and a long-term goal of getting through school.

Laboratory and field studies of time discounting find that discount rates are often much greater in the short run than in the long run, which reflects hyperbolic discount functions (Kirby $\&$ Herrnstein, 1995). The attractiveness of the reward increases when the reward can be obtained immediately. 
PROBLEMS

OF EDUCATION

IN THE $21^{\text {st }}$ CENTURY

Volume 39, 2012

If the learner is able to stifle the quick gain, this is volition. In the absence of strong volition for learning or paternalistic limitation of non-academic activity, realisation of alternative I will give higher utility than alternative II when the immediate reward is just round the corner. Volition entails "plans to sustain motivation and implement goals" (Corno, 2000, p. 659). For the learner, motivational conflicts may emerge between immediate options and a long-term goal, such as graduating from upper-secondary school. The volitional processes are therefore complex, and different metaphors are used to describe this complexity. One idea is that different selves take turns (Metcalfe \& Mischel, 1999); the self is viewed as comprising several decision-making systems that may be in conflict with one another (Ainslie, 2001). The strategic interaction of successive motivational states within the person is explained by the bargaining as an ad hoc explanation of the struggle. The volitional processes according to the valuation of rewards and punishments here are seen as inner bargaining processes in which "any plan we make at one moment must be sold to ourselves at future moments" (Ainslie, 2005, p. 14).

Motivation, in this perspective, will have its basis in goals. A long-term and highlyvalued goal might be being accepted for a specific course after the end of upper-secondary school education. In a short-term perspective, however, the immediate pleasures derived from personal actions may weigh more heavily than the long-term goals. In the absence of personal discipline to override short-term impulses, the choices made by pupils will reflect the interests of immediate satisfaction. Volition is the term given to the ability to override impulses in order to attain long-term educational goals. Volition is related to the individual's maturity. Both an individual's personality and their surroundings can affect their proclivity to override tempting impulses. The individual pupil's maturity is regarded as significant in relation to the ability for volition.

Within Norwegian schools 16-year-olds are responsible for making their own decisions, whilst their parents lack the right of access to the school's work plan in relation to their children. The teacher has even more influence over the pupil's motivation and volition. Research indicates that teachers can have relatively large significance for the learning outcomes of pupils.

In this study, the teacher's responsibilities are divided into "teacher press", the building of good relationships to the individual pupil (hereunder termed "relation building") and classroom management. Classroom management can take the form of clearly-expressed demands (warnings and encouragements) on how the pupil will behave in the classroom. For instance, the teacher can set clear boundaries for behaviour, give instructions requiring pupils to pick up school books, begin tasks, et cetera. This is seen as directive behaviour on the part of the teacher. The purpose of classroom management is to influence the pupil's beliefs regarding which alternatives they should focus on and which preferences they should have regarding their own study behaviour (goal-focused motivation). If the teacher succeeds in influencing the beliefs of the pupil, game theory uses the terminology of strategic moves and brinkmanship (Schelling, 1960). If the teacher wishes to influence the preferences of the pupil, game theory describes promises and threats. Classroom management is regarded as a more "hard-boiled" tool for influencing pupil behaviour in relation to specific situations in the classroom (the teacher can also demonstrate "gentle" behaviour). This can be viewed as important for ensuring peace and order and thereby for securing the conditions required for concentration and learning. As such, classroom management can be seen as influencing pupil volition.

Relation building involves creating bonds with the pupil that oblige the pupil to perform well to reciprocate the teacher's positive behaviour. Relation building occurs with reference to the social norms that apply to the interaction between teacher and pupil and can be significant for both the pupil's motivation and volition.

Teacher press occurs both through written work plans which the teacher sets up for a specified period of time, and also by means of verbal communication, which may be addressed collectively or individually. Press is used here to mean the pressure exerted by the teacher 
upon the pupil through the demands of work and expectations of performance in respect to the individual pupil. This pressure can be thought to influence both the pupil's motivation and

volition. Those teaching skills mentioned here interact to strengthen or weaken each other. In other words, an interactive effect between the teacher's skills (classroom management, relation building, and press) and pupil's accommodations is present.

\section{Methodology of Research}

\section{Sample and Implementation}

With the Knowledge Promotion reform in Norway, there are 12 different study programs in the upper-secondary school curriculum plan. All the programs have a compulsory science course in the first year of upper-secondary school. Following Norwegian education authorities' focus on increasing students' interest in science, science was chosen as the focus subject in the survey. The subject is structured into primary areas, each of which contains embedded competence aims. Science has a number of competence aims after the second, fourth, seventh and tenth grades and after the first year of the academic and the vocational study programs offered in upper-secondary school. Students in the vocational programs receive parts of the academic program's science curriculum for the first year of upper-secondary school. However, the competence aims are the same within these areas. The main area of "the budding researcher" is compulsory for all students. Additionally, students study two main areas that the school designates as relevant to the study program.

The empirical study that forms the basis for the analyses was completed with seven upper-secondary schools located in the Norwegian capital, Oslo. The research study was implemented with the help of a research assistant who travelled around to the schools to administer an anonymous, paper-based questionnaire in the classes. In total, 48 science classes took part, coming from five of the twelve different study programs. A total of 1,112 students voluntarily participated. The survey response rate was high and close to $100 \%$.

The intake point average among the seven schools chosen was 40.9. The intake point score is calculated as the sum of 11 marks after the 10th grade (scale from 1 to 6). This is somewhat higher than the average for all upper-secondary schools in Oslo (39.3). The intake point average among the seven schools varied between 37.5 and 44.2. Among the upper-secondary schools in Oslo there is a variation between about 29 and 48 points. In other words, the upper-secondary schools in the sample had from medium to high intake scores.

\section{Instruments}

Students answered a personally administered questionnaire with closed-ended questions on, among other aspects, motivation, volition, classroom management, teacher relation building, and teacher press. The focus was on academic aspects related to a specific school subject, in this case science, as previously stated.

The work is done within a classical test theoretical paradigm (Crocker \& Algina, 1986) where psychological constructs are operationalized through a set of individual questions that are asked of the students. The students were asked to respond to questions that included the 5-point Likert-scale with alternative response choices: Strongly disagree (1), Disagree (2), Neither agree or disagree (3), Agree (4) and Strongly agree (5).

Constructs based on the questionnaire will be studied in the following; two constructs related to pupil's volition and motivation and three related to teacher's skills. Table 1 gives an overview of the constructs under study, with example items. 
PROBLEMS

OF EDUCATION

IN THE $21^{\text {st }}$ CENTURY

Volume 39,2012

Table 1. Constructs with example items.

\begin{tabular}{|l|l|l|}
\hline \multicolumn{2}{|c|}{ Constructs } & \multicolumn{1}{c|}{ Example item } \\
\hline \multirow{3}{*}{$\begin{array}{l}\text { Pupil's volition and } \\
\text { motivation }\end{array}$} & Pupil volition & Mainly I do my homework at the last minute (reversed) \\
\cline { 2 - 3 } & Pupil motivation & $\begin{array}{l}\text { It is important for me to learn as much as possible in science } \\
\text { this school year }\end{array}$ \\
\hline \multirow{3}{*}{ Teacher's skills } & Teacher press & \begin{tabular}{l} 
The science teacher makes high demands of us students. \\
\cline { 2 - 3 }
\end{tabular} \\
\cline { 2 - 3 } & Teacher classroom manage- & $\begin{array}{l}\text { There is disorder and disruption when we have science } \\
\text { (reversed). }\end{array}$ \\
\cline { 2 - 3 } & Teacher relational building & $\begin{array}{l}\text { It is OK to discuss feelings, worries and frustrations with the } \\
\text { science teacher. }\end{array}$ \\
\hline
\end{tabular}

The analyses were conducted using SPSS 18 and AMOS 18. The sample size analysed consisted of 1,060 students after excluding students having missing values. To assess the measurement reliability of the indicators for each of the subscales Cronbach's alpha was used. Alpha coefficients of .70 or higher were considered to be acceptable (Nunnally \& Bernstein, 1994). The Cronbach's alpha was below .70 for three subscales and above for three. The internal consistency is considered acceptable.

The assessments of both the measurement and the structural model are based on the $p$ value for the $\chi^{2}$-statistic, RMSEA (root mean square error of approximation), NFI (Normed fit index), GFI (Goodness-of-fit index), and TLI (Tucker-Lewis index). The standard criteria $p>$ 0.05 , NFI, GFI and TLI $>0.95$ and RMSEA $<0.05$ have been used for good fit, and $p>0.05$ and NFI, GFI and TLI $>0.90$ and RMSEA $<0.10$ for acceptable fit between the model and the data (Kline, 2005; Blunch, 2008). The fit indices (Figure 1) for the structural model are considered acceptable.

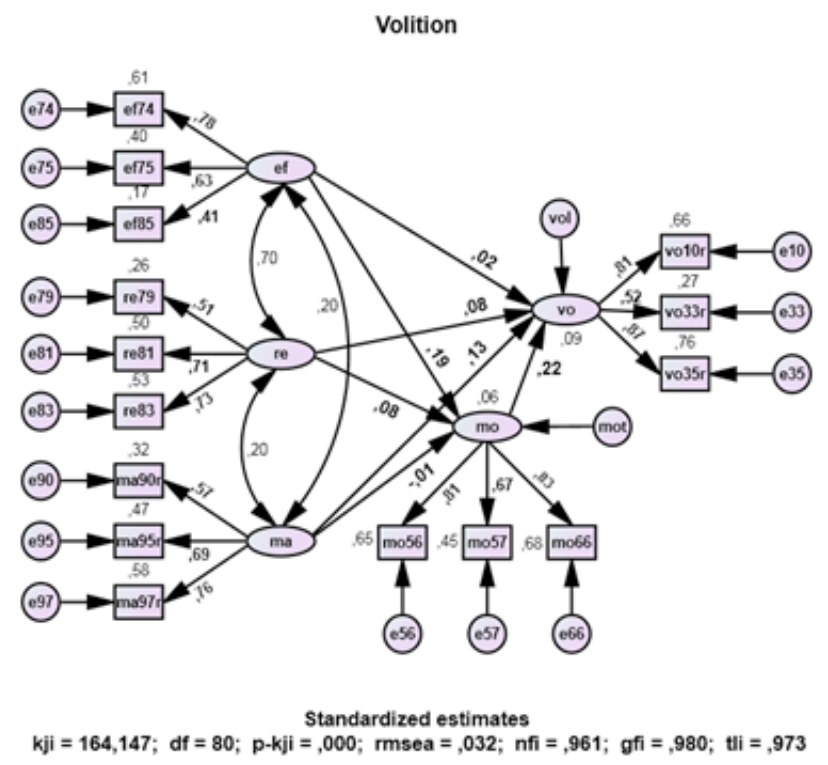

Figure 1: A structural model: Teacher classroom management (ma), teacher relational building (re), teacher press (ef), pupil motivation (mo), pupil volition (vo). $\mathbf{N}=1,060$. 
The results in Figure 1 show that classroom management has a moderate direct effect (path coefficient $=0.13$ ) on pupil volition, whilst the teacher's press has a moderately-powerful direct effect (path coefficient $=0.19$ ) on pupil motivation. The teacher's relationship-building efforts have a rather low direct effect (path coefficient $=0.08$ ) on both pupil motivation and volition. The direct effect from motivation to volition is moderately strong (path coefficient $=$ 0.22). In general, these path coefficients have moderately low values. This means that teacher influence on pupil motivation and volition seems to exist, but the effects of the teaching skills studied here are not especially powerful. Some of the path coefficients have very low values, whilst others are moderately strong. In total, the model statistically explains nine per cent of the variance in the dependent variable volition.

\section{Discussion}

To the extent that the teacher is important for pupil volition, it is classroom management that seems to be the most meaningful tool for affecting pupil volition. The teacher's directive influence over the short-term options faced by the pupil can also help the pupil to cut off a behavioural impulse that occurs to satisfy a short-term need. As long as the pupil understands this and recognises the teacher's corrective work it is effective. In the Norwegian school culture, there are however limits for the kinds of tools that the teacher can employ as part of classroom management (White paper, 2008). If the teacher's intervention is perceived as unfair, for instance, a process can easily occur in which the pupils spend time and energy in opposition. This interpretation implies that effective classroom management is management that is perceived as straightforward and fair. The teacher's credibility as enforcer of rules and regulations is at stake over this. The elbow room available for the teacher is not great. For instance, in Norway it is prohibited to close the door on pupils arriving late to class. This issue has been raised at the highest levels in the Ministry of Education, and the Norwegian authorities have determined that the teacher cannot shut out pupils who arrive late (Dagsavisen, 2009). The weight of the teacher's personality, therefore, has even greater significance for whether or not the teacher will be able to influence pupil volition by means of classroom management. As an indication of the strength of the subjective perception factor amongst the pupils, measurements of how differently the same pupils judge the ability of different teachers in respect of classroom management are looked at.

The teacher's press appears to affect pupil motivation and to an insignificant degree pupil volition. This can be interpreted as suggesting that teacher pressure is perceived through the good vibrations in teacher-pupil interaction. When the teacher persuades the pupils that persistence in study is important, this occurs through motivation. Persuading pupils occurs through rhetorical practice. Rhetoric is the study of how teachers, for instance, perform convincingly in their communication with the pupils. In view of the significance of rhetorical skills in persuading pupils, it is astonishing that the study of rhetoric is entirely absent from Norwegian teacher education.

The relationship-building effect is slightly weaker than the classroom management effect in this study. On the other hand, the path coefficient between relationship building and teacher press is high at 0.70 . This can be interpreted as meaning that relationship building and pressure to learn work together. However, the path coefficients between press and classroom management and between relationship building and classroom management are rather lower $(0.20)$. The interpretation could be that classroom management is a more distinct skill than teacher press and relationship building. The teacher is faced with demanding tasks in the exercise of their role when the pupils are Norwegian 16-year-olds. The pupils have significant rights (for instance 
PROBLEMS

OF EDUCATION

IN THE $21^{\text {st }}$ CENTURY

Volume 39,2012

36

that it is the teacher who has the burden of evidence if the teacher lacks enough grades to set the teacher-attributed grade for the year) but the teacher has "a clearly-defined responsibility for what the pupils learn" (Stoltenberg, 2008). To some extent the visions of pupil influence and teacher accountability can be seen as conflicting goals. The teacher has to navigate in highly-demanding waters in which the culturally-distinct factors clearly direct what is and is not regarded as effective teacher behaviour. The margin of error in classroom management is not great, but can probably be increased if the teacher chooses to be consistent in his strategic deliberations concerning the type of rules and regulations that are to apply in the different classrooms (Emmer et al., 2006). If a teacher does this, it can avoid an unnecessary tug-of-war to determine what rules are to be applicable in respect to classroom behaviour (Evertson \& Weinstein, 2006). Such a strategy will be more powerful if the school leadership also supports a common strategy for classroom management.

It is powerfully rooted in folk psychology that much self-determination is better than little. In the study of 16-year-old pupils' volition, it is not necessarily so evident that that much self-determination is better than little. Pupils can beneficially have some limitations on their behaviour to help them reach their long-term goals of achieving success in education. This study indicates that the teacher can make an impact especially by using classroom management as a tool, although the effect is not great. This can either mean that the potential for this tool is not great or that the teacher makes too little use of it. It is difficult to provide a concrete and definite answer to this. Here experimental studies which could isolate the significance of one aspect are needed. There is a fairly rich international corps of theoretical literature concerning the field of classroom management (for instance Emmer et al., 2006), but it is not certain that the conclusions drawn there are highly relevant in the context of Norwegian society. There is more than anecdotal evidence suggesting that there are clear cultural differences in the teacher's elbow room for the exercise of authority (Stigler \& Hiebert, 1999).

It was not possible to investigate statistical associations between pupil motivation and volition on the one hand and pupil performance (measured, as "value added" through the course of an academic year). Norwegian law has established rules for anonymity in this type of survey and it is not possible to couple our data to information about grades achieved. On the other hand, other research shows a clear connection between pupil use of volitional strategies and performance (Duckworth \& Seligman, 2005; Tangney et al., 2004). This makes us believe that volition forms an important category for the teacher in the work of influencing pupils' learning.

\section{Strengths and Limitations}

The strength of this study is that it has been carried out with a relatively large pool of respondents and that there has been negligible leakage in the carrying out of the empirical survey. Apart from those who were ill at the time of the survey, all pupils who were invited took part. This means that the statistical conclusion validity is relatively strong. The psychometric characteristics of the structural model also have good fit characteristics, which is also a substantial strength. In addition, the model is theory generated, which means that it is possible to regard the estimated path coefficients as reflecting some kind of causality (although researchers are not able to isolate the causality factors).

However, the contributions of this study should also be viewed in light of several limitations. Firstly, it should be emphasised that relatively little quantitative research has been carried out in relation to youth cultures in Norwegian schools. A cross-sectional study will only represent an instant image of a phenomenon. It is inherently true that statistical associations are not the same as causality. Motivation precedes volition and use of learning strategies. However, it can also be argued that effects from, for instance, teacher leadership towards learners operate in the opposite direction to that assumed in our hypothetical model. More research along the 
same lines will help understanding of the assumed causal relationships and of the mechanisms that are assumed to be responsible for the factors that have been measured.

The relations in the model estimated may not be linear. The optimal value of, for instance, classroom management may be lower than the optimal value of the scale. Furthermore, there is a need to include factors from outside the school system in order to study what kinds of factors influence the mobilizing of effort on the part of learners.

The empirical material covers seven schools in Oslo, Norway. The Oslo bias leaves some uncertainty about whether the selection is representative of 16-year-old Norwegian pupils. The material is not sufficiently comprehensive to study the differences between types of schools in a meaningful statistical analysis. Another possible improvement for future studies is to examine some cases in depth in order to attain a better understanding of the phenomena being studied.

There is a need to view the results of such surveys in tandem with new methodologies, for instance qualitative studies of teacher-learner interactions and parent-youth interactions that can address the complexities of the variable interactions. Studying the dynamics of student-student interactions is an interesting, but demanding, research approach. Controlled experiments are beyond the realms of possibility for educational researchers. Longitudinal and quasi-experimental studies of this sort are needed in order to come closer to inferences about causality.

A further limitation with this study is the use of self-reported questionnaire data. The subjective component of such data is undeniable. Independent judgments can provide interesting data about a learner's perceived conceptions and attitudes, but it is difficult to carry out this process whilst honouring promises of anonymity.

\section{Implications for Practice}

Despite its limitations, this study contributes to our understanding of how teachers may influence pupil motivation and volition among Norwegian 16-year-olds. If the associations between the independent and the dependent variables represent causal relationships, our findings may have implications for practice. Firstly, this study provides a moderate basis of evidence for claiming the presence of the teacher's perceived influence over volition, but to a surprisingly modest degree. Classroom management emerges as the most central tool for influencing volition. One practical implication of this is that teacher education, induction programs, and schools should place emphasis on suitable tools for classroom management and on the skills of students and established teachers in this respect. In addition, teacher press and relational building are tools that appear to have the capacity to affect pupil motivation. Here too, both teacher-education establishments and schools should be more aware of how studentteachers and established teachers can develop their skills in exercising pressure to learn in order to influence pupil motivation.

\section{Conclusions}

This study shows that teacher influence on pupil motivation and volition is surprisingly small when measured through path coefficients. However, two important nuances are important: the teacher can influence volition by means of classroom management and also by building positive teacher-student relations. In addition, there is a fairly clear empirical relationship between motivation and volition. The main conclusion has to be that teachers appear to have a moderate impact on pupil volition. This may be interpreted as meaning that 16 -year-old pupils have a significant right to self-determination in the Norwegian school system. 
PROBLEMS

OF EDUCATION

IN THE $21^{\text {st }}$ CENTURY

Volume 39, 2012

\section{References}

Ainslie, G. (2001). Breakdown of Will. Cambridge: Cambridge University Press.

Ainslie, G. (2005). A selectionist model of the ego: Implications for self-control. In: N. Sebanz \& W. Prinz (Eds.) Disorders of Volition. Cambridge, MA: MIT Press.

Blunch, N. J. (2008). Introduction to Structural Equation Modelling using SPSS and AMOS. London: Sage Publications.

Boekaerts, M. (1999). Self-regulated learning: Where we are today. International Journal of Educational Research, 31(6), 445-457.

Boekaerts, M., \& Corno, L. (2005). Self-regulation in the classroom: A perspective on assessment and intervention. Applied Psychology: An International Review, 54 (2) 199-231.

Corno, L. (2000). Special double issue on conceptions of volition: theoretical investigation and studies of practice. International Journal of Educational Research, 33, 659-663.

Corno, L. (2004). Introduction to the special issue work habit and work styles: Volition in education. Teachers College Record, 106 (9), 1669-1694.

Crocker, L., \& Algina, J. (1986). Introduction to Classical and Modern Test Theory. Forth Worth: Harcourt Brace Jovanovich College Publishers.

Dagsavisen (2009). Ikke lov å bortvise elever fra skoletimer. February $5^{\text {th }}$ Dagsavisen (Retrieved from http://www.dagsavisen.no/innenriks/article396656.ece)

Duckworth, A. L., \& Seligman, M. E. (2005). Self-Discipline outdoes IQ in predicting academic performance of adolescents. Psychological Science, 16 (12), 939-944.

Elster, J. (1979). Ulysses and the Sirens. Cambridge: Cambridge University Press.

Emmer, E. T., Evertson, C. M., \& Worsham, M. E. (2006). Classroom Management for Middle and High School Teachers (7th ed.), Boston, MA: Allyn \& Bacon.

Evertson, C. M., \& Weinstein, C. S., (2006). Classroom management as a field of inquiry. In C. Evertson \& C. Weinstein (Eds.), The Handbook of Classroom Management: Research, Practice, \& Contemporary Issues. (pp. 3-15). Mahwah, NJ: Lawrence Erlbaum.

Gollwitzer, P. M. (1999). Implementation Intentions: Strong effects of simple plans, American Psychologist, 54 (7), 493-503.

Green, L., \& Myerson, J. (2004). A discounting framework for choice with delayed and probabilistic rewards. Psychological Bulletin, 130 (5), 769-792.

Heckhausen, H. (1977). Achievement motivation and its constructs: A cognitive model. Motivation and Emotion, 1, 183-329.

Kirby, K. N., \& Herrnstein, R. J. (1995). Preference reversal due to myopic discounting of delayed reward. Psychological Science, 6, 83-89.

Kline, R. B. (2005). Principle and Practice of Structural Equation Modelling. New York: The Guildford Press.

Kuhl, J. (1985). Volitional mediators of cognitive-behavior consistency: Self-regulatory processes and action versus state orientation. In: J. Kuhl \& J. Beckmann (Eds.) Action Control: From Cognition to Behavior (pp. 89-100), Berlin: Springer Verlag.

McCann, E. J., \& Turner, J. E. (2004). Increasing student learning through volitional control. Teachers College Record, 106 (9), 1695-1714.

Metcalfe, J., \& Mischel, W. (1999). A hot/cool system analysis of delay of gratification: Dynamics of willpower. Psychological Review, 106 (1), 3-19.

Nunnally, J. C., \& Bernstein, I. H. (1994). Psychometric Theory (3rd ed.) New York: McGraw-Hill.

Pintrich, P. R. (2000). The role of goal orientation in self-regulated learning. In: Boekarts, M. Pintrich, P. R. \& Zeidner, M. (Eds.): Handbook of Self-discipline. San Diego: Academic Press.

Schelling, T. C. (1960). The Strategy of Conflict. Harvard University Press, Cambridge, MA.

Stigler, J. W., \& Hiebert, J. (1999). The Teaching Gap, New York: Free Press. 
Eyvind ELSTAD, Knut-Andreas CHRISTOPHERSEN, Are TURMO. The Influence of Teacher Skills on Pupil Volition in Science Learning: a Norwegian Investigation of the Studying Behaviours of 16-Year-Olds

\begin{tabular}{l} 
PROBLEMS \\
OF EDUCATION \\
IN THE 21 $1^{\text {st }}$ CENTURY \\
Volume 39, 2012 \\
\hline 39
\end{tabular}

Stoltenberg, J. (2008). Statsministerens nyttårstale 2008 (Retrieved from http://www.regjeringen.no/ $\mathrm{nb} / \mathrm{dep} / \mathrm{smk} /$ Statsministerens-kontor/Statsminister_Jens_Stoltenberg/Taler-og-artikler/2008/ Nyttarstale-2008.html?id=495221

Tangney, J. P., Baumeister, R. F., Boone, A. L. (2004). High self-control predicts good adjustment, less pathology, better grades, and interpersonal success. Journal of Personality, 72, 271-322.

White paper (2003). Culture for learning. White paper no. 10, Oslo: Ministry of Education.

White paper (2008). The teacher. The role and education. White paper no. 11, Oslo: Ministry of Education.

Winne, P. H. (2004). Putting volition to work in education. Teachers College Record, 106 (9), 18791887.

Wolters, C. (2003). Regulation of motivation: Evaluating an underemphasized aspect of self-regulated learning. Educational Psychologist, 38 (4), 189-205.

Zimmerman, B. J. (1998). Developing self-fulfilling cycles of academic discipline: An analysis of exemplary instructional models. In D. H. Schunk \& B. J. Zimmerman (Eds.): Self-regulated Learning: From Teaching to Self-reflective Practice. New York: The Guilford Press.

Zimmerman, B. J. (2000). Attaining self-regulation: A social cognitive perspective. In M. Boekaerts, P. R. Pintrich, \& M. Zeidner (Eds.), Handbook of Self-regulation (pp. 13-39). San Diego: Academic Press.

Advised by Laima Railiene, University of Siauliai, Lithuania

Received: January 12, 2012

Accepted: January 29, 2012

\begin{tabular}{|ll|}
\hline Eyvind Elstad & $\begin{array}{l}\text { Dr.polit., Professor, Department of Teacher Education and School Re- } \\
\text { search, University of Oslo, P.O. Box } 1099 \text { Blindern, } 0317 \text { Oslo, Norway. } \\
\text { E-mail: eyvind.elstad@ils.uio.no } \\
\text { Website: http://www.uv.uio.no/ils/personer/vit/eyvindel/index.html }\end{array}$ \\
\hline Knut-Andreas Christophersen & $\begin{array}{l}\text { Cand. polit., Assistant Professor, Department of Political Science, Univer- } \\
\text { sity of Oslo, P.O. Box 1097 Blindern, 0317 Oslo, Norway. } \\
\text { E-mail: k.a.christophersen@stv.uio.no } \\
\text { Website: http://www.sv.uio.no/isv/personer/vit/knutac/index.html }\end{array}$ \\
\hline \multirow{2}{*}{ Are Turmo } & $\begin{array}{l}\text { Dr.scient., Associate Professor, Department of Teacher Education and } \\
\text { School Research, University of Oslo, P.O. Box 1099 Blindern, 0317 Oslo, } \\
\text { Norway. } \\
\text { E-mail: are.turmo@gmail.com } \\
\text { Website: http://www.uv.uio.no/ils/personer/vit/aret/index.html }\end{array}$ \\
\hline
\end{tabular}

